\title{
Review \\ Mechanisms Underlying Connexin Hemichannel Activation in Disease
}

\author{
Raf Van Campenhout ${ }^{1,+(\mathbb{D})}$, Ana Rita Gomes ${ }^{1,+}$, Timo W.M. De Groof ${ }^{2} \mathbb{D}$, Serge Muyldermans ${ }^{3}(\mathbb{D}$, \\ Nick Devoogdt ${ }^{2}$ iD and Mathieu Vinken ${ }^{1, *}$
}

1 Department of Pharmaceutical and Pharmacological Sciences, Vrije Universiteit Brussel, Laarbeeklaan 103, 1090 Brussels, Belgium; Raf.Van.Campenhout@vub.be (R.V.C.); Ana.Rita.Coelho.Gomes@vub.be (A.R.G.)

2 Department of Medical Imaging, In Vivo Cellular and Molecular Imaging Laboratory, Vrije Universiteit Brussel, Laarbeeklaan 103, 1090 Brussels, Belgium; Timo.De.Groof@vub.be (T.W.M.D.G.); ndevoogd@vub.be (N.D.)

3 Laboratory of Cellular and Molecular Immunology, Vrije Universiteit Brussel, Pleinlaan 2, 1050 Brussels, Belgium; Serge.Muyldermans@vub.be

* Correspondence: Mathieu.Vinken@vub.be; Tel.: +32-2-4774587

+ These authors contributed equally to this work.

check for updates

Citation: Van Campenhout, R.;

Gomes, A.R.; De Groof, T.W.M.;

Muyldermans, S.; Devoogdt, N.; Vinken, M. Mechanisms Underlying Connexin Hemichannel Activation in Disease. Int. J. Mol. Sci. 2021, 22, 3503. https://doi.org/10.3390/ijms22073503

Academic Editor: Lih Kuo

Received: 15 March 2021

Accepted: 26 March 2021

Published: 28 March 2021

Publisher's Note: MDPI stays neutral with regard to jurisdictional claims in published maps and institutional affiliations.

Copyright: (c) 2021 by the authors. Licensee MDPI, Basel, Switzerland This article is an open access article distributed under the terms and conditions of the Creative Commons Attribution (CC BY) license (https:// creativecommons.org/licenses/by/ $4.0 /)$.

\begin{abstract}
Gap junctions and connexin hemichannels mediate intercellular and extracellular communication, respectively. While gap junctions are seen as the "good guys" by controlling homeostasis, connexin hemichannels are considered as the "bad guys", as their activation is associated with the onset and dissemination of disease. Open connexin hemichannels indeed mediate the transport of messengers between the cytosol and extracellular environment and, by doing so, fuel inflammation and cell death in a plethora of diseases. The present mini-review discusses the mechanisms involved in the activation of connexin hemichannels during pathology.
\end{abstract}

Keywords: connexin hemichannel; pathology; mechanism

\section{Introduction}

Although the cell plasma membrane features an impermeable double phospholipid layer structure, cross-membrane trafficking of biomolecules and ions is essential to control various cell processes [1]. Cell plasma membrane transport proteins include different membrane proteins that enable such transfer. Among those are gap junctions, which form cell-to-cell junctions that facilitate direct intercellular communication between cells by allowing the passage of small and hydrophilic molecules, including glucose, glutamate, glutathione, adenosine triphosphate (ATP), cyclic adenosine monophosphate, inositol triphosphate and ions, such as calcium, sodium and potassium [1]. These communicating cell-to-cell junctions serve as gatekeepers for many physiological processes [2,3]. They arise from the interaction of two hemichannels, which in turn are built up by six connexin proteins at the cell plasma membrane surface of adjacent cells. Today, more than 20 different connexin species have been identified. The connexin family members share a common structure consisting of four transmembrane domains, two extracellular loops, one cytosolic loop, one cytosolic carboxyterminal tail and one cytosolic amino tail (Figure 1). The different connexin family members are designated based upon their molecular weight as predicted by cDNA sequencing. In this respect, connexin 43 (Cx43), which is the most abundantly expressed connexin variant, has a molecular mass of $43 \mathrm{kDa}$ [1-3].

Over the past two decades, it has become clear that connexin hemichannels also provide an autonomous communication pathway for communication on their own, independent of their role as structural precursors of gap junctions [4]. While gap junctions mediate intercellular communication, connexin hemichannels support the transport of messengers between the cytosol and the extracellular environment. Unlike gap junctions, connexin hemichannels become predominantly active under pathological conditions 
(Table 1) [2,3,5]. The current mini-review provides an overview of the machinery involved in connexin hemichannel opening in disease.

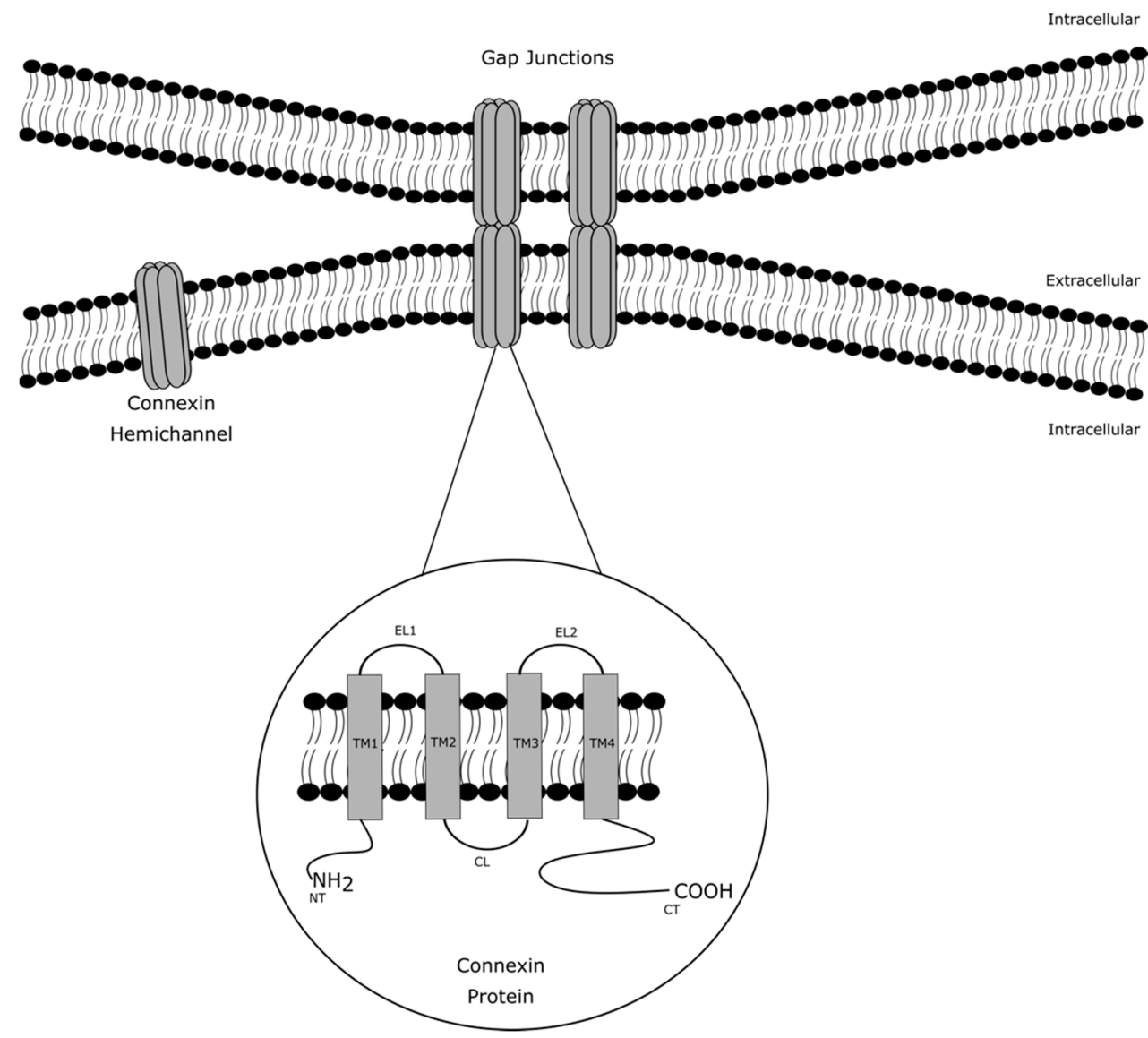

Figure 1. Architecture of gap junction, connexin hemichannels and connexin proteins. Gap junctions arise from the interaction of two connexin hemichannels of adjacent cells. A connexin hemichannel is built up by six connexin proteins. A connexin protein consists of four transmembrane domains (TM1-4), two extracellular loops (EL1-2), one cytosolic loop (CL), one cytosolic carboxyterminal tail (CT) and one cytosolic amino tail (NT).

Table 1. Mechanisms underlying connexin hemichannel activation in disease.

\begin{tabular}{|c|c|c|c|}
\hline Pathological Condition & Connexin Species & $\begin{array}{l}\text { Mechanism of Connexin } \\
\text { Hemichannel Activation }\end{array}$ & References \\
\hline Bone remodelling processes & $\mathrm{C} \times 43$ & Mechanical stimulation & {$[6-8]$} \\
\hline Cardiac ischemia/reperfusion injury & $\mathrm{C} \times 43$ & $\begin{array}{l}\text { Phosphorylation of connexin } \\
\text { proteins }\end{array}$ & [9-12] \\
\hline Cataract & Cx50 & Oxidative stress & [13] \\
\hline \multirow{2}{*}{ Charcot-Marie-Tooth disease } & \multirow{2}{*}{ Cx32 } & $\begin{array}{l}\text { Extracellular calcium ion } \\
\text { concentration }\end{array}$ & {$[14,15]$} \\
\hline & & $\begin{array}{l}\text { Changes in transmembrane } \\
\text { voltage }\end{array}$ & {$[16,17]$} \\
\hline Keratitis-ichthyosis-deafness syndrome & $\mathrm{C} \times 26$ & $\mathrm{pH}$ fluctuation & [18-23] \\
\hline $\begin{array}{l}\text { Neuroinflammatory } \\
\text { conditions }\end{array}$ & Cx43 & $\begin{array}{l}\text { Intracellular calcium ion } \\
\text { concentration }\end{array}$ & [24] \\
\hline $\begin{array}{l}\text { Systemic inflammatory } \\
\text { response }\end{array}$ & Cx43 & $\begin{array}{l}\text { Intracellular calcium ion } \\
\text { concentration }\end{array}$ & [25] \\
\hline
\end{tabular}




\section{Role of Connexin Hemichannels in Inflammation and Cell Death}

\subsection{Inflammation}

The involvement of connexin hemichannels in inflammation and cell death has been well documented in a variety of studies using genetic knock-out animals, knockdown of connexin expression and connexin hemichannels inhibitors [26-28]. Both processes result from tissue responses against infections, chemical insults and physical injury $[29,30]$. Inflammation is a cohesion of reaction mechanisms that initiates the process of pathogen clearance and tissue repair. At the cellular level, canonical inflammasome activation requires two signals (Figure 2). The interaction of damage-associated and pathogen-associated molecular patterns with Toll-like receptors of immune cells induces inflammation [31]. This promotes the transfer of nuclear factor (NF) $-\kappa \beta$ to the nucleus to activate gene expression. Consequently, the genes encoding the premature forms of interleukin (IL)- $1 \beta$ and IL-18 are transcriptionally activated, and the proteins are cleaved to their mature form by caspase 1 in the cytosol. The latter requires a second signal, as nucleotide-binding oligomerization domain leucine rich repeat and pyrin domain-containing protein 3 (NLP3) inflammasome formation leads to activation of caspase 1 . Connexin hemichannels play a prominent role in the initiation of inflammation, because they act as activators of the NLP3 inflammasome pathway by releasing ATP [31,32]. Pathogenic stimuli drive the opening of connexin hemichannels, whereby extracellular ATP molecules can stimulate P2X7 receptors. The activation of these P2X7 receptors results in a decrease of intracellular potassium ions, which is a trigger of NLP3 inflammasome activation [33]. In this way, purinergic P2X7 receptors promote activation of the inflammasome pathway to release IL-1 $\beta$ and IL-18 in the extracellular environment and influence the production of other inflammatory mediators, such as IL-6, tumour necrosis factor (TNF)- $\alpha$ and nitric oxide [31,32,34]. This interplay between connexin hemichannels and NLP3 inflammasome activation plays a pivotal role in initiation of disease pathology. In this respect, it has been well documented that aberrant Cx43 hemichannel activity underlies renal damage in chronic kidney disease. Biopsy material from patients with diabetic nephropathy, an inflammatory-associated disease that represents approximately half of patients with end-stage kidney failure, show an upregulation of $\mathrm{Cx} 43$ protein production in the tubular epithelia. This increased expression of $\mathrm{C} \times 43$ mediates the onset of this disease by mediating the extracellular release of ATP molecules. Thus, P2X7 signalling and NLP3 inflammasome activation are stimulated. In this way, Cx43 hemichannel activity provokes inflammatory damage and phenotypic changes that predispose tubular injury in chronic kidney disease $[35,36]$. Similarly, activation of the NLP3 inflammasome pathway contributes to diabetic retinopathy, a complication of diabetes that can results in vision loss. By blocking Cx43 hemichannels in an ex vivo human organotypic retinal culture model of diabetic retinopathy, it was seen that NLP3 inflammasome activation was hindered. Consequently, $\mathrm{Cx} 43$ hemichannel modulation turns down the release of pro-inflammatory cytokines [37]. In addition, other triggers of NLP3 inflammasome activation, including, $\mathrm{pH}$ fluctuation, oxidative stress and calcium ion mobilization, are well-known regulators of connexin hemichannels $[38,39]$. 


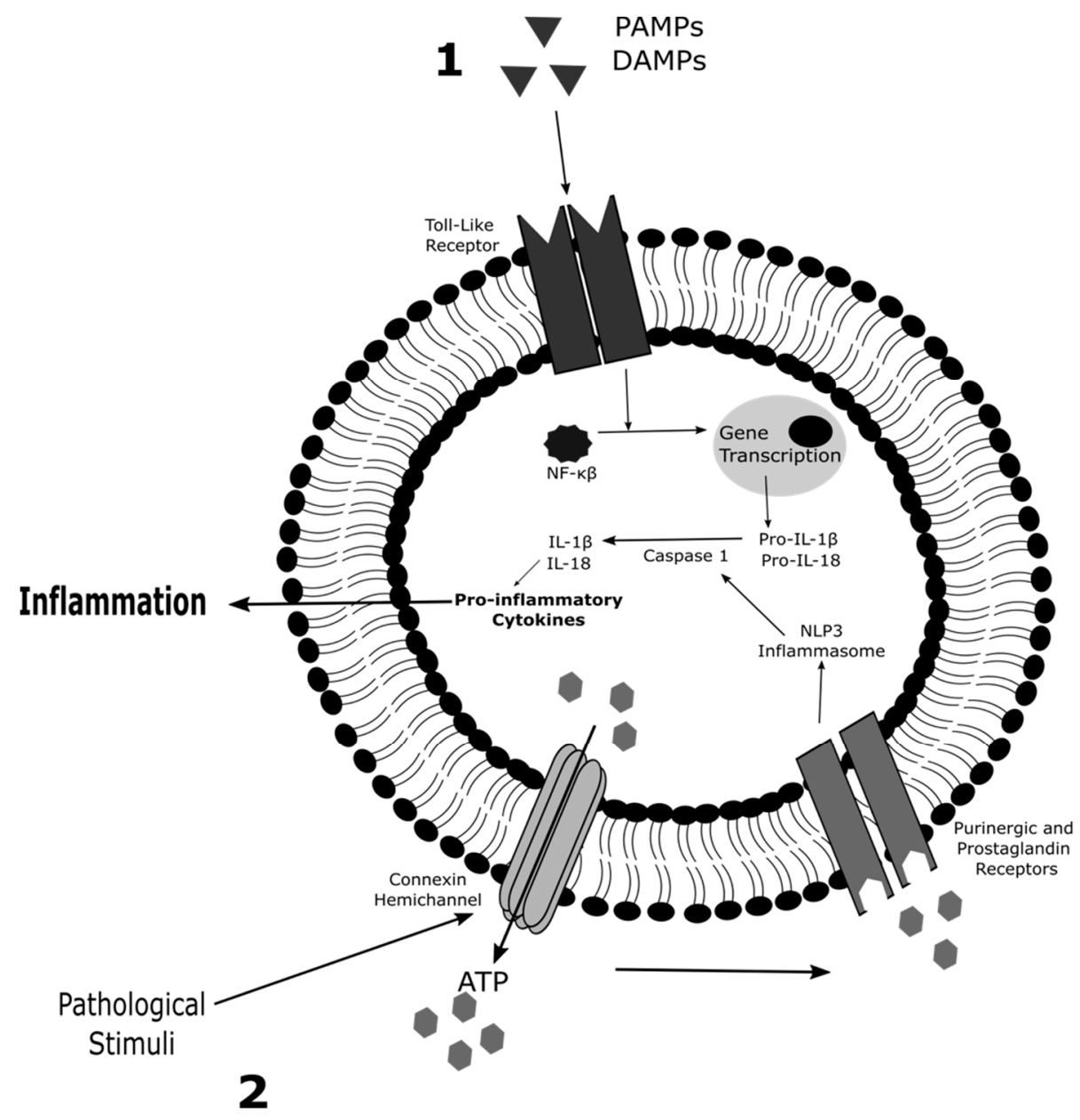

Figure 2. Role of connexin hemichannels in canonical inflammation activation. Canonical inflammasome activation requires two signals. (1) Damage-associated molecular patterns (DAMPs) and pathogen-associated molecular patterns (PAMPs) interact with Toll-like receptors of immune cells to induce inflammation. The binding of DAMPs and PAMPs promotes the transfer of nuclear factor $(\mathrm{NF})-K \beta$ to the nucleus to activate gene expression. Thus, the transcription of the genes encoding premature forms of interleukin (IL)- $1 \beta$ and IL-18 is triggered. (2) Pathogenic stimuli drive the opening of connexin hemichannels, promoting the extracellular release of adenosine triphosphate (ATP). Extracellular ATP molecules stimulate P2X7 receptors, leading to nucleotide-binding oligomerization domain leucine rich repeat and pyrin domain-containing protein 3 (NLP3) inflammasome activation. NLP3 inflammasome activation triggers the onset of caspase 1, which influences the inflammatory process by cleaving pro-IL- $1 \beta$ and pro-IL-18 to their mature form and producing other pro-inflammatory cytokines.

The inflammatory environment on its own is another triggering factor for connexin signalling and can contribute to disease progression. As such, pro-inflammatory cytokines act as activators of $\mathrm{C} \times 43$ hemichannels of mouse astrocytes. While pro-inflammatory treatment reduces gap junction-mediated intercellular communication, a mixture of IL-1 $\beta$ and TNF- $\alpha$ increases Cx43 hemichannel activity in murine astrocytes. This induced opening of Cx43 hemichannels affects the trafficking of glucose molecules. Thus, activated Cx43 hemichannels enhance the cellular uptake of glucose, which might explain the metabolic changes of astrocytes involved in brain inflammation [40]. Similarly, promoted Cx43 hemichannel activity is seen after treating human endothelial cells with IL- $1 \beta$ and TNF- $\alpha$ in combination with glucose, a condition that occurs in cardiovascular diseases [41]. The opening of Cx43 hemichannels is associated with extracellular ATP release, which stimulates mitogen-activated protein kinases, nitric oxide production, cyclo-oxygenase-2 and 
purinergic and prostaglandin receptors. Thus, several signalling cascades are triggered, leading to endothelial dysfunction and cell damage [41]. The involvement of connexin channels in inflammation is also demonstrated by the differential effects of lipopolysaccharide, the major component of the outer membrane of Gram-negative bacteria, on gap junctions and connexin hemichannels. Lipopolysaccharide induces an inflammatory response by activating the arachidonic acid pathway. This arachidonic acid pathway regulates inflammatory responses through forcing the biosynthesis of prostaglandins and thromboxane A2 from arachidonic acid. While lipopolysaccharide inhibits gap junctions, the response of connexin hemichannels depends on the balance between kinase-mediated phosphorylation of connexins and arachidonic acid effects [42]. In this respect, predominance of the arachidonic acid effect can support pathogenic-pore behaviour by stimulating paracrine ATP signalling [42]. For readers who want to learn more about the details and specific aspects on the involvement of connexin hemichannels in inflammation and associated diseases, references to papers that extensively describe and discuss the prominent role of connexin hemichannels in inflammation have been provided [33,34,43]. In short, studies show that the passage of calcium ions and ATP through connexin hemichannels stimulates inflammatory signalling pathways in different acute and chronic diseases, like acetaminopheninduced liver failure, lung inflammation and diabetic retinopathy $[33,34,43]$. In this respect, it has become clear that connexin hemichannels mediate cellular communication underlying inflammatory diseases in several organs $[33,34,43]$.

\subsection{Cell Death}

Connexin hemichannels can participate in cell death in many ways. The opening of connexin hemichannels has been observed in different types of cell death, including apoptosis, necrosis, necroptosis and ferroptosis [44-47]. As such, connexin hemichannels participate in the cellular release and uptake of essential metabolites and toxic substances. Thus, Cx32 hemichannels are involved in neurotoxicity. Mouse microglia, treated with TNF- $\alpha$, are more prone to cell death as the induced opening of $C \times 32$ hemichannels causes the release of glutamate, which promotes neurotoxicity [48]. Vice versa, cell death also affects connexin hemichannels. Human lens epithelial cells feature functional connexin hemichannels at the cell plasma membrane by expressing Cx32, Cx46 and Cx50 proteins. Exposure of these cells to linoleic acid results in an induction of cell death. Connexin hemichannels are involved in initiation of apoptosis, since treatment of lens cells with linoleic acid opens connexin hemichannels. This leads to elevations in intracellular calcium ion concentrations [49]. Such overload of calcium ions can contribute to cell death via signalling cascades leading to phagocytosis, endoplasmic reticulum stress, mitochondrial permeabilization and nuclear changes. Influx of calcium ions also affects connexin hemichannels and associated transfer of vital molecules [49,50]. Another role of connexin hemichannels in cell death includes communication of messages towards surrounding cells in a paracrine manner [51,52]. Rat glioma cells transfected with $c \times 43$ can be triggered with cytochrome $\mathrm{C}$ to undergo apoptosis. Comparison with non-transfected cells demonstrated that both gap junctions and $\mathrm{Cx} 43$ hemichannels contribute to the spatial spreading of apoptosis through calcium ion fluxes. While gap junctions can only mediate apoptotic cell death in close proximity, $\mathrm{Cx} 43$ hemichannels also affect healthy cells beyond the 'gap junction-associated area' [51]. This bystander signalling effect of Cx43 hemichannels has also been shown in brain microvascular endothelial cells that were isolated from mice. X-rays can cause DNA damage and cell death in surrounding cells, and connexin hemichannels are associated with these radiation-induced bystander effects. The opening of Cx43 hemichannels propagates damage to non-irradiated cells by participating in signalling cascades involving calcium ions, reactive oxygen species (ROS), ATP and nitric oxide [52]. 


\section{Regulation of Connexin Hemichannels}

\subsection{Mechanical Stimulation}

Evidence for the opening of connexin channels in response to mechanical stimulation has been predominantly shown in chicken and murine osteocytes. Osteocytes, the most abundant cells present in skeletal adult bone tissue, are regulators of bone remodelling processes. Bone remodelling is involved in the reshaping and replacement of bone following injury, including fractures. An imbalance of bone remodelling processes results in major bone loss and osteoporosis in patients. Osteocytes play a central role in the initiation of bone remodelling, as they are mechanosensitive cells that sense stress within the bone $[53,54]$. Mechanical stimulation of bone induces fluid flow in the lacuna canalicular network and osteocytes respond to this shear stress by releasing intracellular prostaglandin E2 (PGE2) via Cx43 hemichannels [6]. Cx43 hemichannel activity in response to mechanical stimulation in osteocytes is adaptive. The opening of Cx43 hemichannels is correlated with the magnitude of fluid flow shear stress [55]. Fluid flow shear stress initiates interaction between integrin $\alpha-5$, a cell plasma membrane protein, and the carboxyterminal tail of Cx43 [7]. The interplay between these 2 proteins is enhanced by protein kinase B-mediated phosphorylation of $\mathrm{C} \times 43$ on serine373. This modification stabilizes complex formation with 14-3-30, an adapter protein that regulates Cx43 hemichannel activity by stimulating translocation towards the cell plasma membrane surface [56]. By doing so, the opening of Cx43 hemichannels is enhanced. However, continuous shear stress leads to a gradual closing of Cx43 hemichannels [55]. It has been shown that closure of Cx43 hemichannels is regulated by one of its substrates. The release of PGE2 initiates an accumulation effect that leads to closure of hemichannels by promoting Cx43 phosphorylation through extracellular signal-regulated kinases [8]. Thus, the mechanical stimulation of osteocytes results in open and closed Cx43 hemichannels, and controls extracellular PGE2 levels. PGE2 does not only regulate Cx43 hemichannel activity, but also acts as mediator for the prevention of bone related diseases. PGE2 preserves osteocyte viability, inhibits osteoclast functionality and stimulates differentiation of osteoblasts to increase bone formation [57]. However, the prominent role of PGE2 in bone pathology remains difficult to unravel, as it stimulates osteoclast formation at high concentrations as well [58]. This biphasic effect seems to be important in health and disease. Endogenous levels of prostaglandins regulate bone physiology whereas abnormalities in PGE2 quantities are linked with pathology [59]. Consequently, the connection between Cx43 hemichannel activity through mechanical stimulation and release of PGE2 by osteocytes may be of paramount importance in bone pathology.

\section{2. $p H$ Fluctuation}

The keratitis-ichthyosis-deafness (KID) syndrome is a rare disorder characterized by skin lesions, hearing loss and vascularizing keratitis. KID is associated with mutations in the $c x 26$ gene that lead to excessive opening of Cx26 hemichannels [18]. One of the Cx26 KID mutations substitutes a valine for alanine at amino acid position 40 (alanine40valine) and affects activity of Cx26 hemichannels. Xenopus oocytes expressing human Cx26 proteins show sensitivity towards $\mathrm{pH}$ fluctuation, as adjusting extracellular $\mathrm{pH}$ values from 8.0 to 6.5 decreases $\mathrm{C} 26$ hemichannel currents. Furthermore, this inhibitory effect on Cx26 hemichannels by $\mathrm{pH}$ is less recorded with oocytes harbouring the alanine40valine mutant [19]. Given that physiological $\mathrm{pH}$ levels reduce $\mathrm{C} \times 26$ hemichannel activity and Cx26 protein levels control dermal homeostasis by regulating keratinocyte differentiation and proliferation, it is hypothesized that insensitivity of $\mathrm{C} \times 26$ hemichannels towards $\mathrm{pH}$ might underlie skin disorders in KID patients [20-22]. While the epidermis is slightly acidic, the environment of the deeper layers of the skin is more neutral. Since the alanine40valine point mutation at the boundary of the first transmembrane domain and the first extracellular domain of $\mathrm{C} \times 26$ results in abnormal opening of $\mathrm{C} \times 26$ hemichannels in this $\mathrm{pH}$ range, aberrant Cx26 hemichannel activity of keratinocytes in the basal layers might contribute to the development of hyperkeratosis [19]. Open Cx26 hemichannels give rise to leakage of 
essential biomolecules, like ATP, and the resulting ionic imbalance mediated by these leaky Cx26 hemichannels is associated with abnormal proliferation of keratinocytes and pathological features $[19,21,22]$. However, the mechanism of pH-mediated Cx26 hemichannel activity remains elusive. Protonation of $\mathrm{Cx} 26$ could promote activation of its hemichannels, since an acidic $\mathrm{pH}$ drives a conformational change of $\mathrm{C} \times 26$ proteins to reform channels from a closed to an open transition state [23]. However, increasing the extracellular $\mathrm{pH}$ can also trigger hemichannel opening. In this respect, human cervical cancer cells transfected with $c \times 43$ show sensitivity towards alkalinization. Raising extracellular $\mathrm{pH}$ values from 7.4 to 8.5 leads to an enhanced Cx43 hemichannel activity, which was measured through ethidium uptake, compared to wild-type cervical cancer cells [60].

\subsection{Calcium Concentration}

Another regulator of connexin hemichannel activity is the amount of calcium ions present in the extracellular environment and cytosol. Physiological conditions preserve sufficient high concentrations of surrounding calcium ions to keep connexin hemichannels in a closed state [61]. For hemichannels composed of Cx26, Cx32 and Cx43, it has been shown that reducing the calcium concentration at the extracellular side leads to activation. As such, the cascading decrease of calcium concentration is accompanied by a gradual enlargement of the pore diameter $[14,61,62]$. This reversible process is explained by the ability of calcium ions to bind extracellular parts of the connexin hemichannel to unbalance the open hemichannel configuration. So, the removal of calcium ions allows rearrangement of connexin proteins, which induces connexin hemichannel-mediated diffusion processes [61]. The interaction between calcium ions and Cx32 hemichannels is mediated by aspartic amino acids present in the second extracellular loop. Two aspartic amino acids of each Cx26 protein are responsible for the formation of a ring of 12 aspartic amino acids in the hemichannel configuration, which is an extracellular region for docking of surrounding calcium ions. In this respect, mutants harbouring site-directed point mutations of human Cx32 at aspartic acid169 or aspartic acid178 in oocytes from Xenopus laevis generate hemichannels that are less sensitive towards calcium-ion dependent triggering compared to wild-type hemichannels [14]. This aberrant connexin hemichannel activity is also linked with pathological conditions. The naturally occurring mutation in the $c x 32$ gene replaces aspartic acid for tyrosine at position 178. This amino acid substitution is known as one of the 260 different mutations causing X-linked Charcot-Marie-Tooth disease, an inherited form of demyelinating neuropathy. Since this mutation is associated with calcium ion dysregulation, uncontrolled opening of hemichannels can induce disturbance of transportation of ions and small molecules across the cell plasma membrane of Schwann cells and underlies the pathogenesis of neuropathy $[14,15]$. Furthermore, intracellular calcium ions are involved in connexin hemichannel opening as well. As a consequence of larger cytosolic calcium ion concentrations, a calmodulin-depending cascade is activated to open connexin hemichannels via intermediate signalling steps $[63,64]$. The implication of Cx43 hemichannels and intracellular calcium ions in pathological conditions has been demonstrated by injecting mice with TNF- $\alpha$ to induce a systemic inflammatory response syndrome characterized by overproduction and secretion of cytokines and chemokines into the circulation. Whereas blocking $\mathrm{Cx} 43$ hemichannels protects mice against TNF- $\alpha$-induced mortality, hypothermia and vascular permeability alterations, stimulation of hemichannel opening has the opposite effect. Whole-cell voltage clamp experiments on human cervical cancer cells overexpressing Cx43 show that TNF- $\alpha$ induces $C \times 43$ hemichannel opening depending on calcium [25]. The interplay between intracellular calcium ions and connexin hemichannels is also associated with several neuroinflammatory conditions. As such, open Cx43 hemichannels contribute to degranulation processes in mast cells in Alzheimer's disease, amyotrophic lateral sclerosis and harmful stress conditions [24]. 


\subsection{Changes in Transmembrane Voltage}

The voltage regulation of connexin hemichannel activity is mainly a consequence of voltage-driven changes in connexin protein conformation. Differences in electrical potential between the cytoplasmic and extracellular environment change the position of amino acids, whereby gating properties are affected [65]. The voltage-mediated activity of connexin hemichannels shows 2 distinct forms of hemichannel gating, namely a fast and a slow gating mechanism, which are associated with transitions between open and sub-conductance states, and transitions between the open and closed state through intermediate conductance states, respectively $[65,66]$. This sensitivity towards transmembrane voltage is underscored by voltage sensors that are present in connexin proteins. As such, the slow gating mechanism induces conformational changes of connexin proteins by coordinating a rotation of the first transmembrane domain and a tilt of connexin subunits $[66,67]$. In this respect, the asparagine amino acid at position 159 of Cx26 proteins is responsible for forming voltage-activated hemichannels. Electrophysiology measurements in xenopus oocytes and murine neuroblastoma cells expressing rat, sheep or human Cx26 proteins show that the single evolutionary amino acid change at position 159 of the rodent protein accounts for voltage insensitive hemichannels. Furthermore, the introduction of a structural change by substituting aspartic acid with asparagine in rat $\mathrm{C} \times 26$ restores voltage dependency. Given that mutations within the $c x 26$ gene affects the functionality of its hemichannels under physiological control of transmembrane voltage, the role of Cx26 mutants and associated hemichannels in pathological activity may be critical [16]. For Cx32, serine85cysteine mutants, which are associated with X-linked Charcot-Marie-Tooth disease, generate more voltage-sensitive connexin hemichannels. Current-voltage relations observed with xenopus oocytes expressing human $\mathrm{C} \times 32$ protein and its serine85cysteine mutant show an increased open probability for mutant $\mathrm{C} \times 32$ hemichannels present at the cell plasma membrane surface. Since Cx32 is expressed by Schwann cells, the serine85cysteine mutation may cause dysfunction of these cells by abnormalities in trafficking of ions and small metabolites and lead to clinical manifestations of X-linked Charcot-Marie-Tooth disease [17].

\subsection{Oxidative Stress}

Oxidative stress is a critical determinant in the pathogenesis of various diseases, such as ischemia, atherosclerosis and neurodegenerative disorders. The oxidative stress state is characterized by increased ROS formation and impaired antioxidant systems [68-70]. When cellular metabolism is stimulated to produce additional ROS, oxidative stress can drive pathological processes by compromising DNA, disrupting membranal layers, inactivating membrane-bound proteins, triggering proteases and affecting signal transduction mechanisms [71]. Cigarette smoke extract and hydrogen peroxide cause opening of connexin hemichannels. Measurements with rat fibroblastoid cells expressing Cx43 and connexin deficient mouse neuroblastoma cells implicate that activation of these hemichannels is evoked by depolarisation of the cell plasma membrane. Oxidative stress and associated hemichannel opening predispose cells to cell death. Following treatment of neuroblastoma cells with cigarette smoke extract, apoptotic changes are observed, while incubation with connexin hemichannel blockers prevents early cell death, cell shrinkage and the formation of apoptotic bodies [72]. In contrast, lens fibre cells benefit from activation of connexin hemichannels. Chicken embryo fibroblast cells transfected with $c x 50$ are opened by hydrogen peroxide to significantly reduce the level of apoptosis. Counterparts with the Cx50 proline88serine construct, a mutation that is associated with cataract, are rather impeded and no reduction of apoptosis occurs. The protective effect of Cx50 hemichannels against oxidative stress is mediated by the cellular uptake of the antioxidant glutathione [13]. Cx43 hemichannels are also involved in preserving cells against osmotic stress induced-damage. During skeletal aging, which is associated with accumulation of ROS and osteocyte cell death, bones become fragile and more likely to break. The critical role for $\mathrm{Cx} 43$ hemichannels in this pathogenesis has been demonstrated by treating murine osteocyte-like cells with hydrogen peroxide. The latter evokes cell death, but a dose-dependent effect on Cx43 
hemichannel activity was seen as well. Since blocking of $\mathrm{Cx} 43$ hemichannels exacerbates cell death, a protective role for open Cx43 hemichannels has been shown in osteocytes [73].

\subsection{Phosphorylation}

Connexin proteins can undergo several posttranslational modifications, including phosphorylation $[74,75]$. In fact, phosphorylation is a major regulator of connexin hemichannel opening [76,77]. With the exception of Cx26, all connexins are phosphoproteins. Connexins are substrates for many kinases and the outcome of this posttranslational modification depends on the nature of the kinase and connexin as well on the cellular context $[5,75]$. In this context, phosphorylation of serine at position 368 of $\mathrm{Cx} 43$ controls connexin hemichannel communication. Following injection of Xenopus laevis oocytes with Cx43 cRNA, uptake of carboxyfluorescein measurements show that blocking of protein kinase $C$, a member of the mitogen-activated protein kinase family, increases connexin hemichannel permeability [77]. As expected, the phosphorylation status of Cx43 proteins plays a critical role during disease [9]. Cx43 phosphorylation and dephosphorylation are associated with cardiac ischemia/reperfusion injury. Ischemia leads to dephosphorylation of Cx43 and redistributes gap junction constituents away from intercalated disks. In this way, Cx43 proteins lose their supportive role of coordinating contractile activation and trigger arrythmias in the ischemic heart [10]. Furthermore, relocated Cx43 may operate as open hemichannels. Preventing the loss of critic metabolites, restoring ionic imbalance, hindering cellular swelling and cell rupture via blocking these channels all are protective against myocardial ischemia/reperfusion injury [11,12]. However, it remains difficult to determine a general mechanism for the effects of phosphorylation on connexin hemichannel activity as there is a difference between the connexin family members. Whereas protein kinase C-mediated phosphorylation induces the closure of Cx30 hemichannels in Xenopus laevis, Cx43 hemichannels were unaffected. In this regard, the phosphorylation-dependent regulation of connexin hemichannels is seen as a connexin specie-specific process [78]. Furthermore, protein kinase C-isoforms can differentially modulate connexin hemichannel activity as well. Patch clamp analysis with cells, which were derived from human embryonal kidney cells and transfected with cx43, shows a difference in Cx43 hemichannel electrical conductance upon treatment with various protein kinase inhibitors [79].

\section{Conclusions and Perspectives}

Connexins have been detected in virtually all cell types and organs. They gather in a hexameric hemichannel configuration at the cell plasma membrane surface. Connexin hemichannels become predominantly active in pathological conditions, and support inflammation and cell death. Hereby, open connexin hemichannels are involved in a wide array of pathologies $[2,10,80,81]$. Different mechanisms underly connexin hemichannel activity, as reviewed in this manuscript. However, gaining more in-depth insight into the molecular mechanism remains challenging. Since gap junctions and connexin hemichannels are composed of the same connexin building blocks and allow the passage of identical molecules and ions, it is difficult to distinguish between both channel types. Thus far, techniques monitoring extracellular release of messengers, like ATP, or cytosolic uptake of tracer dyes, such as Lucifer Yellow, are widely used to study connexin hemichannel activity, yet the presence of many other cell plasma membrane transport proteins can interfere with these read-outs [82]. Most importantly, this research area lacks robust connexin hemichannel blockers [2]. At present, connexin hemichannel research still largely relies on the use of peptide-based inhibitors that reproduce specific amino acid sequence in the structure of connexin proteins. In this regard, Gap19 is a synthetic nonapeptide (KQIEIKKFK) targeting the cytoplasmic loop of Cx43. Gap19 prevents interaction between the cytoplasmic loop and carboxyterminal tail, leading to inhibition of Cx43 hemichannels, while leaving Cx43-based gap junctions unaffected [83]. Similarly, Gap24 (GHGDPLHLEEVKC) imitates a sequence in the cytoplasmic loop of Cx32 and inhibits its hemichannels [83]. Despite the promising potential of these mimetic peptides both in vitro and in vivo, their short 
half-life impedes clinical application [84]. Several groups are therefore currently focusing on novel strategies to overcome this issue, including improving stability and selectivity of connexin mimetic peptides [84]. The design of peptides that mimic the carboxyterminal tail of connexin proteins seems particularly interesting for future development of connexin hemichannel inhibitors. Given that amino acid sequences of the carboxyterminal tail differ considerably among connexin species and that this region controls opening of connexin hemichannels, the carboxyterminal tail is considered as a major potential target for peptide-based inhibitors. This is underscored by the $\alpha \mathrm{CT} 1$ peptide, which is currently being tested in clinical trials for the treatment of diabetic foot and venous leg ulcers by switching off $\mathrm{C} \times 43$ hemichannel signalling [84]. In parallel, antibodies specifically targeting connexin hemichannels are being explored [85]. An additional strategy to develop connexin hemichannel inhibitors includes the modulation of existing drugs. Since it was recently found that aminoglycosides, which are broad-spectrum antibiotics, can act as inhibitors of connexin hemichannels, the idea of using small-molecule drugs for the development of new connexin hemichannel inhibitors is gaining more attention [86,87]. In this respect, the generation of kanamycin derivatives has yet resulted in the identification of a lead compound for Cx43 hemichannel inhibition [88]. Another promising small-molecule that regulates connexin hemichannel activity is tonabersat, a member of the benzoylamino-benzopyran family. Tonabersat is a compound that has been identified as $\mathrm{Cx} 43$ hemichannel blocker and shows great potential to impede the role of open connexin hemichannels in inflammation. The drug product of tonabersat, which is currently in clinical trials for the treatment of diabetic retinopathy and age-related macular degeneration, is applicable for oral administration and aims to hinder Cx43-mediated ATP release promoting NLP3 inflammasome activation [89]. Research in these directions should be strongly encouraged, as this may lead to a new generation of drugs to treat a plethora of connexin hemichannel-related pathologies.

Author Contributions: Conceptualization: R.V.C., A.R.G., T.W.M.D.G., S.M., N.D. and M.V.; Original draft preparation: R.V.C. and A.R.G.; Review and editing: T.W.M.D.G., S.M., N.D. and M.V.; Visualization: R.V.C. and A.R.G.; Supervision: M.V.; Funding acquisition: M.V. All authors have read and agreed to the published version of the manuscript.

Funding: This work was financially supported by the European Research Council (Proof-of-Concept grant 861913), the European Future and Emerging Technologies program (grant 858014), the Research Foundation Flanders-Belgium (grants G012318N, G020018N and G0F7219N) and the University Hospital of the Vrije Universiteit Brussel-Belgium (Scientific Fund Willy Gepts).

Institutional Review Board Statement: Not applicable.

Informed Consent Statement: Not applicable.

Data Availability Statement: Not applicable.

Conflicts of Interest: The authors declare no conflict of interest.

\section{References}

1. Van Campenhout, R.; Muyldermans, S.; Vinken, M.; Devoogdt, N.; De Groof, T.W.M. Therapeutic nanobodies targeting cell plasma membrane transport proteins: A high-risk/high-gain endeavor. Biomolecules 2021, 11, 63. [CrossRef]

2. Cooreman, A.; van Campenhout, R.; Ballet, S.; Annaert, P.; Van Den Bossche, B.; Colle, I.; Cogliati, B.; Vinken, M. Connexin and pannexin (hemi)channels: Emerging targets in the treatment of liver disease. Hepatology 2019, 69, 1317-1323. [CrossRef]

3. Vinken, M. Connexin hemichannels: Novel mediators of toxicity. Arch. Toxicol. 2015, 89, 143-145. [CrossRef]

4. Van Campenhout, R.; Cooreman, A.; Leroy, K.; Rusiecka, O.M.; Van Brantegem, P.; Annaert, P.; Muyldermans, S.; Devoogdt, N.; Cogliati, B.; Kwak, B.R.; et al. Non-canonical roles of connexins. Prog. Biophys. Mol. Biol. 2020, 153, 35-41. [CrossRef]

5. Vinken, M.; Vanhaecke, T.; Papeleu, P.; Snykers, S.; Henkens, T.; Rogiers, V. Connexins and their channels in cell growth and cell death. Cell. Signal. 2006, 18, 592-600. [CrossRef]

6. Cherian, P.P.; Siller-Jackson, A.J.; Gu, S.; Wang, X.; Bonewald, L.F.; Sprague, E.; Jiang, J.X. Mechanical Strain Opens Connexin 43 Hemichannels in Osteocytes: A Novel Mechansim for the Release of Prostaglandin. Mol. Biol. Cell 2005, 16, 3100-3106. [CrossRef]

7. Batra, N.; Riquelme, M.A.; Burra, S.; Kar, R.; Gu, S.; Jiang, J.X. Direct regulation of osteocytic connexin 43 hemichannels through AKT kinase activated by mechanical stimulation. J. Biol. Chem. 2014, 289, 10582-10591. [CrossRef] [PubMed] 
8. Riquelme, M.A.; Burra, S.; Kar, R.; Lampe, P.D.; Jiang, J.X. Mitogen-activated protein kinase (MAPK) activated by prostaglandin E2 phosphorylates connexin 43 and closes osteocytic hemichannels in response to continuous flow shear stress. J. Biol. Chem. 2015, 290, 28321-28328. [CrossRef]

9. Schulz, R.; Görge, P.M.; Görbe, A.; Fernandy, P.; Lampe, P.D.; Leybaert, L. Connexin43 is an emerging therapeutic target in ischemia/reperfusion injury, cardioprotection and neuroprotection. Pharmacol. Ther. 2015, 153, 90-106. [CrossRef]

10. Rusiecka, O.M.; Montgomery, J.; Morel, S.; Batista-Almeida, D.; Van Campenhout, R.; Vinken, M.; Girao, H.; Kwak, B.R. Canonical and non-canonical roles of connexin 43 in cardioprotection. Biomolecules 2020, 10, 1225. [CrossRef]

11. Wang, N.; De Vuyst, E.; Ponsaerts, R.; Boengler, K.; Palacios-Prado, N.; Wauman, J.; Lai, C.P.; De Bock, M.; Decrock, E.; Bol, M.; et al. Selective inhibition of Cx43 hemichannels by Gap19 and its impact on myocardial ischemia/reperfusion injury. Basic Res. Cardiol. 2013, 108, 309. [CrossRef]

12. De Smet, M.A.J.; Sipido, K.R.; Leybaert, L. Cx43 hemichannel microdomain signaling at the intercalated disc enhances cardiac excitability. J. Clin. Investig. 2021. [CrossRef]

13. Shi, W.; Riquelme, M.A.; Gu, S.; Jiang, J.X. Connexin hemichannels mediate glutathione transport and protect lens fiber cells from oxidative stress. J. Cell Sci. 2018, 131, jcs212506. [CrossRef]

14. Gómez-Hernández, J.M.; De Miguel, M.; Larrosa, B.; González, D.; Barrio, L.C. Molecular basis of calcium regulation in connexin-32 hemichannels. Proc. Natl. Acad. Sci. USA 2003, 100, 16030-16035. [CrossRef]

15. Ressot, C.; Bruzzone, R. Connexin channels in Schwann cells and the development of the X-linked form of Charcot-Marie-Tooth disease. Brain Res. Rev. 2000, 32, 192-202. [CrossRef]

16. González, D.; Gómez-Hernández, J.M.; Barrio, L.C. Species specificity of mammalian connexin-26 to form open voltage-gated hemichannels. FASEB J. 2006, 20, 2329-2338. [CrossRef]

17. Abrams, C.K.; Bennett, M.V.L.; Verselis, V.K.; Bargiello, T.A. Voltage opens unopposed gap junction hemichannels formed by a connexin 32 mutant associated with X-linked Charcot-Marie-Tooth disease. Proc. Natl. Acad. Sci. USA 2002, 99, 3980-3984. [CrossRef]

18. Levit, N.A.; Sellitto, C.; Wang, H.Z.; Li, L.; Srinivas, M.; Brink, P.R.; White, T.W. Aberrant Connexin26 Hemichannels Underlying Keratitis-Ichthyosis-Deafness Syndrome Are Potently Inhibited by Mefloquine. J. Investig. Dermatol. 2015, 135, $1033-1042$. [CrossRef]

19. Sanchez, H.A.; Bienkowski, R.; Slavi, N.; Srinivas, M.; Verselis, V.K. Altered inhibition of Cx26 hemichannels by $\mathrm{pH}$ and $\mathrm{Zn}^{2+}$ in the A40V mutation associated with keratitis-ichthyosis-deafness syndrome. J. Biol. Chem. 2014, 289, 21519-21532. [CrossRef]

20. Langlois, S.; Maher, A.C.; Manias, J.L.; Shao, Q.; Kidder, G.M.; Laird, D.W. Connexin levels regulate keratinocyte differentiation in the epidermis. J. Biol. Chem. 2007, 282, 30171-30180. [CrossRef]

21. Lee, J.R.; White, T.W. Connexin-26 mutations in deafness and skin disease. Expert Rev. Mol. Med. 2009, 11, e35. [CrossRef] [PubMed]

22. Martin, P.E.; Easton, J.A.; Hodgins, M.B.; Wright, C.S. Connexins: Sensors of epidermal integrity that are therapeutic targets. FEBS Lett. 2014, 588, 1304-1314. [CrossRef] [PubMed]

23. Wang, X.; Xu, X.; Ma, M.; Zhou, W.; Wang, Y.; Yang, L. pH-dependent channel gating in connexin26 hemichannels involves conformational changes in N-terminus. Biochim. Biophys. Acta Biomembr. 2012, 1818, 1148-1157. [CrossRef]

24. Harcha, P.A.; Garcés, P.; Arredondo, C.; Fernández, G.; Sáez, J.C.; van Zundert, B. Mast Cell and Astrocyte Hemichannels and Their Role in Alzheimer's Disease, ALS, and Harmful Stress Conditions. Int. J. Mol. Sci. 2021, 22, 1924. [CrossRef]

25. Delvaeye, T.; De Smet, M.A.J.; Verwaerde, S.; Decrock, E.; Czekaj, A.; Vandenbroucke, R.E.; Lemeire, K.; Gonçalves, A.; Declercq, W.; Vandenabeele, P.; et al. Blocking connexin 43 hemichannels protects mice against tumour necrosis factor-induced inflammatory shock. Sci. Rep. 2019, 9, 16623. [CrossRef]

26. Willebrords, J.; Cogliati, B.; Pereira, I.V.A.; Da Silva, T.C.; Crespo Yanguas, S.; Maes, M.; Govoni, V.M.; Lima, A.; Felisbino, D.A.; Decrock, E.; et al. Inhibition of connexin hemichannels alleviates non-alcoholic steatohepatitis in mice. Sci. Rep. 2017, 7, 8268. [CrossRef]

27. De Bock, M.; Culot, M.; Wang, N.; Bol, M.; Decrock, E.; De Vuyst, E.; Da Costa, A.; Dauwe, I.; Vinken, M.; Simon, A.M.; et al. Connexin channels provide a target to manipulate brain endothelial calcium dynamics and blood-brain barrier permeability. $J$. Cereb. Blood Flow Metab. 2011, 31, 1942-1957. [CrossRef]

28. Dosch, M.; Zindel, J.; Jebbawi, F.; Melin, N.; Sanchez-Taltavull, D.; Stroka, D.; Candinas, D.; Beldi, G. Connexin-43 dependent ATP release mediates macrophage activation during peritonitis. Elife 2019, 8, e42670. [CrossRef]

29. Yang, Y.; Jiang, G.; Zhang, P.; Fan, J. Programmed cell death and its role in inflammation. Mil. Med. Res. 2015, 2, 12. [CrossRef]

30. Chen, L.; Deng, H.; Cui, H.; Fang, J.; Zuo, Z.; Deng, J.; Li, Y.; Wang, X.; Zhao, L. Inflammatory responses and inflammationassociated diseases in organs. Oncotarget 2017, 9, 7204-7218. [CrossRef] [PubMed]

31. Kelley, N.; Jeltema, D.; Duan, Y.; He, Y. The NLRP3 inflammasome: An overview of mechanisms of activation and regulation. Int. J. Mol. Sci. 2019, 20, 3328. [CrossRef] [PubMed]

32. He, Y.; Hara, H.; Núñez, G. Mechanism and Regulation of NLRP3 Inflammasome Activation. Trends Biochem. Sci. 2016, 41, 1012-1021. [CrossRef] [PubMed]

33. Willebrords, J.; Yanguas, S.C.; Maes, M.; Decrock, E.; Wang, N.; Leybaert, L.; Kwak, B.R.; Green, C.R.; Cogliati, B.; Vinken, M. Connexins and their channels in inflammation. Crit. Rev. Biochem. Mol. Biol. 2016, 51, 413-439. [CrossRef] [PubMed] 
34. Zhou, K.Q.; Green, C.R.; Bennet, L.; Gunn, A.J.; Davidson, J.O. The role of connexin and pannexin channels in perinatal brain injury and inflammation. Front. Physiol. 2019, 10,1-21. [CrossRef]

35. Price, G.W.; Chadjichristos, C.E.; Kavvadas, P.; Tang, S.C.W.; Yiu, W.H.; Green, C.R.; Potter, J.A.; Siamantouras, E.; Squires, P.E.; Hills, C.E. Blocking Connexin-43 mediated hemichannel activity protects against early tubular injury in experimental chronic kidney disease. Cell Commun. Signal. 2020, 18, 79. [CrossRef] [PubMed]

36. Hills, C.; Price, G.W.; Wall, M.J.; Kaufmann, T.J.; Chi-Wai Tang, S.; Yiu, W.H.; Squires, P.E. Transforming Growth Factor Beta 1 Drives a Switch in Connexin Mediated Cell-to-Cell Communication in Tubular Cells of the Diabetic Kidney. Cell. Physiol. Biochem. 2018, 45, 2369-2388. [CrossRef] [PubMed]

37. Mugisho, O.O.; Green, C.R.; Zhang, J.; Acosta, M.L.; Rupenthal, I.D. Connexin43 hemichannels: A potential drug target for the treatment of diabetic retinopathy. Drug Discov. Today 2019, 24, 1627-1636. [CrossRef]

38. Pellegrini, C.; Antonioli, L.; Lopez-Castejon, G.; Blandizzi, C.; Fornai, M. Canonical and non-canonical activation of NLRP3 inflammasome at the crossroad between immune tolerance and intestinal inflammation. Front. Immunol. 2017, 8, 1-12. [CrossRef]

39. Yang, Y.; Wang, H.; Kouadir, M.; Song, H.; Shi, F. Recent advances in the mechanisms of NLRP3 inflammasome activation and its inhibitors. Cell Death Dis. 2019, 10, 128. [CrossRef]

40. Retamal, M.A.; Froger, N.; Palacios-Prado, N.; Ezan, P.; Sáez, P.J.; Sáez, J.C.; Giaume, C. Cx43 hemichannels and gap junction channels in astrocytes are regulated oppositely by proinflammatory cytokines released from activated microglia. J. Neurosci. 2007, 27, 13781-13792. [CrossRef]

41. Sáez, J.C.; Contreras-Duarte, S.; Gómez, G.I.; Labra, V.C.; Santibañez, C.A.; Gajardo-Gómez, R.; Avendaño, B.C.; Díaz, E.F.; Montero, T.D.; Velarde, V.; et al. Connexin 43 hemichannel activity promoted by pro-inflammatory cytokines and high glucose alters endothelial cell function. Front. Immunol. 2018, 9, 1-17. [CrossRef]

42. De Vuyst, E.; Decrock, E.; De Bock, M.; Yamasaki, H.; Naus, C.C.; Evans, W.H.; Leybaert, L. Connexin Hemichannels and Gap Junction Channels Are Differentially Influenced by Lipopolysaccharide and Basic Fibroblast Growth Factor. Mol. Biol. Cell 2007, 18, 34-46. [CrossRef]

43. Sáez, J.C.; Green, C. Involvement of connexin hemichannels in the inflammatory response of chronic diseases. Int. J. Mol. Sci. 2018, 19, 2469. [CrossRef]

44. Decrock, E.; Vinken, M.; De Vuyst, E.; Krysko, D.V.; D’Herde, K.; Vanhaecke, T.; Vandenabeele, P.; Rogiers, V.; Leybaert, L. Connexin-related signaling in cell death: To live or let die? Cell Death Differ. 2009, 16, 524-536. [CrossRef] [PubMed]

45. Kalvelyte, A.; Imbrasaite, A.; Bukauskiene, A.; Verselis, V.K.; Bukauskas, F.F. Connexins and apoptotic transformation. Biochem. Pharmacol. 2003, 66, 1661-1672. [CrossRef]

46. Chi, J.; Li, L.; Liu, M.; Tan, J.; Tang, C.; Pan, Q.; Wang, D.; Zhang, Z. Pathogenic connexin-31 forms constitutively active hemichannels to promote necrotic cell death. PLoS ONE 2012, 7, e32531. [CrossRef]

47. Contreras, J.E.; Sanchez, H.A.; Véliz, L.P.; Bukauskas, F.F.; Bennett, M.V.L.; Sáez, J.C. Role of connexin-based gap junction channels and hemichannels in ischemia-induced cell death in nervous tissue. Brain Res. Rev. 2004, 47, 290-303. [CrossRef] [PubMed]

48. Takeuchi, H.; Jin, S.; Wang, J.; Zhang, G.; Kawanokuchi, J.; Kuno, R.; Sonobe, Y.; Mizuno, T.; Suzumura, A. Tumor necrosis factor- $\alpha$ induces neurotoxicity via glutamate release from hemichannels of activated microglia in an autocrine manner. J. Biol. Chem. 2006, 281, 21362-21368. [CrossRef] [PubMed]

49. Figueroa, V.A.; Jara, O.; Oliva, C.A.; Ezquer, M.; Ezquer, F.; Retamal, M.A.; Martínez, A.D.; Altenberg, G.A.; Vargas, A.A Contribution of Connexin Hemichannels to the Decreases in Cell Viability Induced by Linoleic Acid in the Human Lens Epithelial Cells (HLE-B3). Front. Physiol. 2020, 10, 1-13. [CrossRef]

50. Zhivotovsky, B.; Orrenius, S. Calcium and cell death mechanisms: A perspective from the cell death community. Cell Calcium 2011, 50, 211-221. [CrossRef]

51. Decrock, E.; De Vuyst, E.; Vinken, M.; Van Moorhem, M.; Vranckx, K.; Wang, N.; Van Laeken, L.; De Bock, M.; D’Herde, K.; Lai, C.P.; et al. Connexin 43 hemichannels contribute to the propagation of apoptotic cell death in a rat C6 glioma cell model. Cell Death Differ. 2009, 16, 151-163. [CrossRef]

52. Hoorelbeke, D.; Decrock, E.; De Smet, M.; De Bock, M.; Descamps, B.; Van Haver, V.; Delvaeye, T.; Krysko, D.V.; Vanhove, C.; Bultynck, G.; et al. Cx43 channels and signaling via IP3/ $\mathrm{Ca}^{2+}$, ATP, and ROS/NO propagate radiation-induced DNA damage to non-irradiated brain microvascular endothelial cells. Cell Death Dis. 2020, 11, 194. [CrossRef] [PubMed]

53. Schaffler, M.B.; Kennedy, O.D. Osteocyte Signaling in Bone. Curr. Osteoporos. Rep. 2012, 10, 118-125. [CrossRef]

54. Rochefort, G.Y. The osteocyte as a therapeutic target in the treatment of osteoporosis. Ther. Adv. Musculoskelet. Dis. 2014, 6, 79-91. [CrossRef] [PubMed]

55. Siller-Jackson, A.J.; Burra, S.; Gu, S.; Xia, X.; Bonewald, L.F.; Sprague, E.; Jiang, J.X. Adaptation of connexin 43-hemichannel prostaglandin release to mechanical loading. J. Biol. Chem. 2008, 283, 26374-26382. [CrossRef] [PubMed]

56. Burnstock, G. Purinergic signalling: Therapeutic developments. Front. Pharmacol. 2017, 8, 661. [CrossRef]

57. Mirsaidi, A.; Tiaden, A.N.; Richards, P.J. Prostaglandin E2 inhibits matrix mineralization by human bone marrow stromal cell-derived osteoblasts via Epac-dependent cAMP signaling. Sci. Rep. 2017, 7, 2243. [CrossRef]

58. Kaji, H.; Sugimoto, T.; Kanatani, M.; Fukase, M.; Kumegawa, M.; Chihara, K. Prostaglandin E2 Stimulates Osteoclast-like Cell Formation and Bone-Resorbing Activity via Osteoblasts: Role of cAMP-Dependent Protein Kinase. J. Bone Miner. Res. 1996, 11, 62-71. [CrossRef] 
59. Raisz, L.G.; Pilbeam, C.C.; Fall, P.M. Prostaglandins: Mechanisms of action and regulation of production in bone. Osteoporos. Int. 1993, 3, 136-140. [CrossRef]

60. Schalper, K.A.; Sánchez, H.A.; Lee, S.C.; Altenberg, G.A.; Nathanson, M.H.; Sáez, J.C. Connexin 43 hemichannels mediate the $\mathrm{Ca}^{2+}$ influx induced by extracellular alkalinization. Am. J. Physiol. Cell Physiol. 2010, 299, 1504-1515. [CrossRef] [PubMed]

61. Lopez, W.; Ramachandran, J.; Alsamarah, A.; Luo, Y.; Harris, A.L.; Contreras, J.E. Mechanism of gating by calcium in connexin hemichannels. Proc. Natl. Acad. Sci. USA 2016, 113, 7986-7995. [CrossRef]

62. Thimm, J.; Mechler, A.; Lin, H.; Rhee, S.; Lal, R. Calcium-dependent open/closed conformations and interfacial energy maps of reconstituted hemichannels. J. Biol. Chem. 2005, 280, 10646-10654. [CrossRef]

63. De Vuyst, E.; Decrock, E.; Cabooter, L.; Dubyak, G.R.; Naus, C.C.; Evans, W.H.; Leybaert, L. Intracellular calcium changes trigger connexin 32 hemichannel opening. EMBO J. 2006, 25, 34-44. [CrossRef]

64. De Vuyst, E.; Wang, N.; Decrock, E.; De Bock, M.; Vinken, M.; Van Moorhem, M.; Lai, C.; Culot, M.; Rogiers, V.; Cecchelli, R.; et al. $\mathrm{Ca}^{2+}$ regulation of connexin 43 hemichannels in C6 glioma and glial cells. Cell Calcium 2009, 46, 176-187. [CrossRef] [PubMed]

65. Oh, S.; Bargiello, T.A. Voltage regulation of connexin channel conductance. Yonsei Med. J. 2015, 56, 1. [CrossRef] [PubMed]

66. Bargiello, T.A.; Oh, S.; Tang, Q.; Bargiello, N.K.; Dowd, T.L.; Kwon, T. Gating of Connexin Channels by transjunctional-voltage: Conformations and models of open and closed states. Biochim. Biophys. Acta Biomembr. 2018, 1860, 22-39. [CrossRef] [PubMed]

67. Harris, A.L.; Contreras, J.E. Motifs in the permeation pathway of connexin channels mediate voltage and $\mathrm{Ca}^{2+}$ sensing. Front. Physiol. 2014, 5, 113. [CrossRef] [PubMed]

68. Yang, X.; Li, Y.; Li, Y.; Ren, X.; Zhang, X.; Hu, D.; Gao, Y.; Xing, Y.; Shang, H. Oxidative stress-mediated atherosclerosis: Mechanisms and therapies. Front. Physiol. 2017, 8, 600. [CrossRef]

69. Rodrigo, R.; Fernandez-Gajardo, R.; Gutierrez, R.; Matamala, J.; Carrasco, R.; Miranda-Merchak, A.; Feuerhake, W. Oxidative Stress and Pathophysiology of Ischemic Stroke: Novel Therapeutic Opportunities. CNS Neurol. Disord. Drug Targets 2013, 12, 698-714. [CrossRef] [PubMed]

70. Uttara, B.; Singh, A.V.; Zamboni, P.; Mahjan, R. Oxidative Stress and Neurodegenerative Diseases: A Review of Upstream and Downstream Antioxidant Therapeutic Options. Curr. Neuropharmacol. 2009, 7, 65-74. [CrossRef] [PubMed]

71. Birben, E.; Sahiner, U.M.; Sackesen, C.; Erzurum, S.; Kalayci, O. Oxidative stress and antioxidant defense. World Allergy Organ. J. 2012, 5, 9-19. [CrossRef]

72. Ramachandra, S.; Xie, L.H.; John, S.A.; Subramaniam, S.; Lal, R. A novel role for connexin hemichannel in oxidative stress and smoking-induced cell injury. PLoS ONE 2007, 2, e712.

73. Kar, R.; Riquelme, M.A.; Werner, S.; Jiang, J.X. Connexin 43 channels protect osteocytes against oxidative stress-induced cell death. J. Bone Miner. Res. 2013, 28, 1611-1621. [CrossRef] [PubMed]

74. Johnstone, S.R.; Billaud, M.; Lohman, A.W.; Taddeo, E.P.; Isakson, B.E. Posttranslational modifications in connexins and pannexins. J. Membr. Biol. 2012, 245, 319-332. [CrossRef]

75. D’hondt, C.; Iyyathurai, J.; Vinken, M.; Rogiers, V.; Leybaert, L.; Himpens, B.; Bultynck, G. Regulation of connexin- and pannexin-based channels by post-translational modifications. Biol. Cell 2013, 105, 373-398. [CrossRef]

76. Pogoda, K.; Kameritsch, P.; Retamal, M.A.; Vega, J.L. Regulation of gap junction channels and hemichannels by phosphorylation and redox changes: A revision. BMC Cell Biol. 2016, 17, 137-150. [CrossRef]

77. Fiori, M.C.; Reuss, L.; Cuello, L.G.; Altenberg, G.A. Functional analysis and regulation of purified connexin hemichannels. Front. Physiol. 2014, 5, 71. [CrossRef]

78. Alstrøm, J.S.; Hansen, D.B.; Nielsen, M.S.; MacAulay, N. Isoform-specific phosphorylation-dependent regulation of connexin hemichannels. J. Neurophysiol. 2015, 114, 3014-3022. [CrossRef] [PubMed]

79. Hawat, G.; Baroudi, G. Differential modulation of unapposed connexin 43 hemichannel electrical conductance by protein kinase C isoforms. Pflug. Arch. Eur. J. Physiol. 2008, 456, 519-527. [CrossRef] [PubMed]

80. Pfenniger, A.; Chanson, M.; Kwak, B.R. Connexins in atherosclerosis. Biochim. Biophys. Acta Biomembr. 2013, 1828, 157-166. [CrossRef]

81. Vinken, M. Introduction: Connexins, pannexins and their channels as gatekeepers of organ physiology. Cell. Mol. Life Sci. 2015, 72, 2775-2778. [CrossRef]

82. Leroy, K.; Pieters, A.; Tabernilla, A.; Cooreman, A.; Van Campenhout, R.; Cogliati, B.; Vinken, M. Targeting gap junctional intercellular communication by hepatocarcinogenic compounds. J. Toxicol. Environ. Health Part B Crit. Rev. 2020, 23, 255-275. [CrossRef]

83. Willebrords, J.; Maes, M.; Crespo Yanguas, S.; Vinken, M. Inhibitors of connexin and pannexin channels as potential therapeutics. Pharmacol. Ther. 2017, 180, 144-160. [CrossRef]

84. Caufriez, A.; Böck, D.; Martin, C.; Ballet, S.; Vinken, M. Peptide-based targeting of connexins and pannexins for therapeutic purposes. Expert Opin. Drug Discov. 2020, 15, 1213-1222. [CrossRef] [PubMed]

85. Buratto, D.; Donati, V.; Zonta, F.; Mammano, F. BBA-Molecular Basis of Disease Harnessing the therapeutic potential of antibodies targeting connexin hemichannels. BBA Mol. Basis Dis. 2021, 1867, 166047. [CrossRef] [PubMed]

86. Fiori, M.C.; Krishnan, S.; Kjellgren, A.; Cuello, L.G.; Altenberg, G.A. Inhibition by Commercial Aminoglycosides of Human Connexin Hemichannels Expressed in Bacteria. Molecules 2017, 22, 2063. [CrossRef] [PubMed]

87. Natha, C.M.; Vemulapalli, V.; Fiori, M.C.; Chang, C.-W.T.; Altenberg, G.A. Connexin Hemichannel Inhibitors with a Focus on Aminoglycosides. Biochim. Biophys. Acta Mol. Basis Dis. 2021, 1867, 166115. [CrossRef] [PubMed] 
88. Subedi, Y.P.; Kjellgren, A.; Roberts, P.; Montgomery, H.; Thackeray, N.; Fiori, M.C.; Altenberg, G.A.; Chang, C.T. Amphiphilic aminoglycosides with increased selectivity for inhibition of connexin 43 (Cx43) hemichannels. Eur. J. Med. Chem. 2020, 203, 112602. [CrossRef]

89. Louie, H.H.; Shome, A.; Kuo, C.Y.; Rupenthal, I.D.; Green, C.R.; Mugisho, O.O. Connexin43 hemichannel block inhibits NLRP3 inflammasome activation in a human retinal explant model of diabetic retinopathy. Exp. Eye Res. 2021, 202, 108384. [CrossRef] 